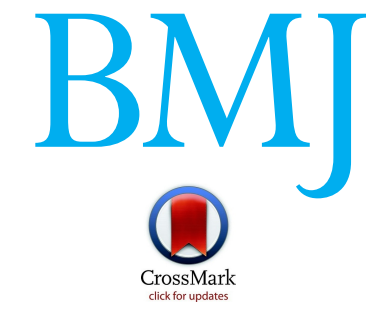

\section{Video decision support tool for advance care planning in dementia: randomised controlled trial}

Angelo E Volandes, instructor, ${ }^{1}$ Michael K Paasche-Orlow, associate professor, ${ }^{2}$ Michael J Barry, professor, ${ }^{1}$ Muriel R Gillick, professor, ${ }^{3}$ Kenneth L Minaker, professor, ${ }^{1}$ Yuchiao Chang, senior statistician, ${ }^{1}$ E Francis Cook, professor, ${ }^{4}$ Elmer D Abbo, assistant professor, ${ }^{5}$ Areej El-Jawahri, research fellow, ${ }^{1}$ Susan L Mitchell, associate professor $^{6}$

\section{ABSTRACT}

Objective To evaluate the effect of a video decision support tool on the preferences for future medical care in older people if they develop advanced dementia, and the stability of those preferences after six weeks.

Design Randomised controlled trial conducted between 1 September 2007 and 30 May 2008.

Setting Four primary care clinics (two geriatric and two adult medicine) affiliated with three academic medical centres in Boston.

Participants Convenience sample of 200 older people ( $\geq$ 65 years) living in the community with previously scheduled appointments at one of the clinics. Mean age was 75 and $58 \%$ were women.

Intervention Verbal narrative alone $(n=106)$ or with a video decision support tool $(n=94)$.

Main outcome measures Preferred goal of care: life prolonging care (cardiopulmonary resuscitation, mechanical ventilation), limited care (admission to hospital, antibiotics, but not cardiopulmonary resuscitation), or comfort care (treatment only to relieve symptoms). Preferences after six weeks. The principal category for analysis was the difference in proportions of participants in each group who preferred comfort care. Results Among participants receiving the verbal narrative alone, 68 (64\%) chose comfort care, 20 (19\%) chose limited care, 15 (14\%) chose life prolonging care, and three (3\%) were uncertain. In the video group, 81 (86\%) chose comfort care, eight ( $9 \%$ ) chose limited care, four $(4 \%)$ chose life prolonging care, and one (1\%) was uncertain $\left(X^{2}=13.0, d f=3, P=0.003\right)$. Among all participants the factors associated with a greater likelihood of opting for comfort care were being a college graduate or higher, good or better health status, greater health literacy, white race, and randomisation to the video arm. In multivariable analysis, participants in the video group were more likely to prefer comfort care than those in the verbal group (adjusted odds ratio 3.9, 95\% confidence interval 1.8 to 8.6). Participants were reinterviewed after six weeks. Among the 94/106 (89\%) participants re-interviewed in the verbal group, 27 (29\%) changed their preferences $(\mathrm{k}=0.35)$. Among the $84 / 94$ (89\%) participants re-interviewed in the video group, five
(6\%) changed their preferences $(K=0.79)(P<0.001$ for difference).

Conclusion Older people who view a video depiction of a patient with advanced dementia after hearing a verbal description of the condition are more likely to opt for comfort as their goal of care compared with those who solely listen to a verbal description. They also have more stable preferences over time.

Trial registration Clinicaltrials.gov NCT00704886.

\section{INTRODUCTION}

Respecting patients' preferences for treatment is a key component of high quality end of life care. ${ }^{1-4}$ Traditionally, physicians help patients to engage in advance care planning for future health states by describing hypothetical situations such as advanced dementia and by exploring possible goals of care. ${ }^{56}$ This traditional approach is limited because it is challenging to realistically envision hypothetical future disease states such as dementia from verbal descriptions, ${ }^{7}$ descriptions are inconsistent among providers, ${ }^{8-15}$ and the degree to which patients understand verbal descriptions of complex medical conditions depends on their level of health literacy.

Visual images can improve communication of complex health information ${ }^{16-19}$ and inform decision making at the end of life..$^{20-22}$ In our previous investigations, a video decision support tool for advanced dementia seemed to improve communication and decision making for patients by helping them to visualise future health states. ${ }^{20-22}$ However, there were significant shortcomings to these studies: they were conducted in healthy middle aged patients; they used a before and after study design that did not allow comparison of the video to the standard advance care planning approach of a verbal narrative; they did not measure knowledge of the disease to test whether understanding of the disease improved; and they did not follow patients' preferences over time.

To address these shortcomings, we conducted a randomised controlled trial of the video decision support tool among a diverse group of older patients to study the video with a higher level of rigour. We 


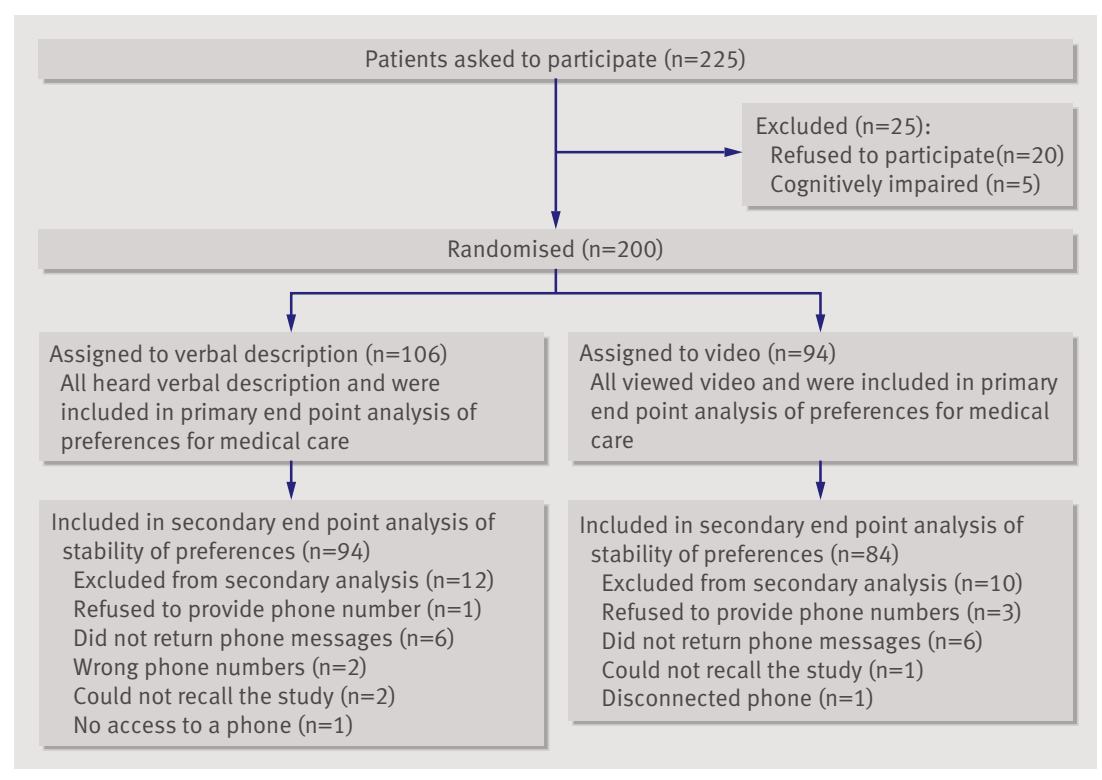

Fig 1| Flow of participants through study
These comprised an urban geriatric clinic, a suburban geriatric clinic, an urban adult primary care clinic, and a suburban adult primary care clinic. Recruitment occurred between 1 September 2007 and 30 May 2008. Clinic staff gave all scheduled English speaking patients aged 65 or over a leaflet outlining the study after patients registered for their clinic visit, which was scheduled as part of their usual care. At the end of the visit, clinic staff asked patients if they were interested in participating in the study. If patients indicated interest, the research team initially interviewed them for eligibility. Eligibility criteria included ability to communicate in English, ability to provide informed consent, and absence of moderate or severe cognitive impairment based on a short portable mental status questionnaire (SPMSQ) score of $\geq 7$ (scores $<7$ indicate moderate or severe cognitive impairment). ${ }^{25}$

\section{Study design and randomisation}

After we obtained informed consent, all patients who met the eligibility criteria were randomised into one of two groups: listening to a verbal narrative describing advanced dementia (control group) or listening to the same verbal narrative followed by watching a two minute video depicting a patient with advanced dementia (intervention group). We used simple randomisation based on a computer generated scheme. Individual assignments were concealed in numbered envelopes, half of which were made available to each interviewer. One randomisation list was generated for all four clinics. At the end of the trial, the randomisation order of participants was checked against the computer generated list. A trained member of the research team followed a structured script to collect data in a quiet room in the clinic area.

For both groups, the interviewer read aloud the verbal narrative describing advanced dementia (see appendix on bmj.com). This description was based on the functional assessment staging (FAST) stage $7 \mathrm{a}^{26}$ The FAST criteria include seven stages of dementia, with the later stages depicting more advanced disease. Stage 7 is further broken down into six substages (7a-7f). Stage $7 \mathrm{a}$ is generally considered the threshold for advanced dementia. The narrative states that advanced dementia is an incurable illness of the brain caused by many years of Alzheimer's disease or a series of strokes. Its salient features are the inability to communicate understandably with others, inability to walk without assistance, and inability to feed oneself.

Participants randomised to the intervention group viewed the video decision support tool on a portable computer after listening to the same verbal narrative. The two minute video depicts the principal features of advanced dementia as described in the narrative. The video presents an 80 year old female patient with advanced dementia together with her two daughters in the nursing home setting (www.bmj.com/video/care_preferences_dementia.dtl; also available at www.ACPdecisions.com). The patient fails to respond to their attempts at conversation (inability to communicate). The patient is next shown

\section{METHODS}

Participants

Participants were recruited from a convenience sample of patients cared for at four primary care clinics located at three teaching hospitals in the greater Boston area. 
being pushed in a wheelchair (inability to ambulate). Lastly, the patient is fed pureed food (inability to feed oneself). Before filming we obtained consent from her designated healthcare proxy to film the patient and to use the video for research purposes.

The development of the video followed a systematic approach, ${ }^{27}$ starting with a review of the literature on dementia and advance care planning. We then used a panel of physicians with an iterative process of comments to review the design, content, and structure of the video intervention. This panel included five geriatricians and five neurologists, all of whom specialise in the care of patients with dementia.

The video was filmed without the use of prompts or stage directions to convey a candid realism. ${ }^{28}$ The principal investigator (AEV) did all filming and editing, following previously published filming criteria. ${ }^{29}$ The video is accompanied by the same narration that was used in the verbal description arm of the study.

\section{Data collection and other variables}

At all four study sites, two members of the research team (AEV and AEJ), who were not blinded to the randomisation group, used structured questionnaires to interview participants before and after they listened to the verbal narrative alone or listened to the narrative and watched the video. At the baseline structured interview (15 minutes) we collected demographic data and data on health status and knowledge about advanced dementia. Sociodemographic data included age, race (self reported), sex, educational status, and marital status. Health status was self rated on a Likert scale as excellent, very good, good, fair, or poor. Participants were also asked if they had had a diagnosis of dementia and whether they had known a person with advanced dementia. We assessed knowledge of advanced dementia with five true/false questions that asked whether advanced dementia is curable and if patients with advanced dementia are able to communicate with others, recognise family members, ambulate, and feed themselves. Knowledge scores therefore ranged from 0-5, with higher scores indicating better knowledge.

Participants underwent a second structured interview (15 minutes) immediately after the intervention. This included knowledge of advanced dementia, preferences for goals of care, health literacy, and, for the video group, comfort with the video decision support tool. The knowledge questions were identical to those asked in the baseline interview.

There were three options for preferences for goals of care: life prolonging care, limited care, and comfort care (see appendix on bmj.com). Researchers verbally described examples of the kinds of care implied by each goal. The first option, life prolonging care, was described as aiming to prolong life at any cost. It translates into all potentially indicated medical care that is available in a modern hospital, including cardiopulmonary resuscitation and treatment in the intensive care unit. The second option, limited care, was described as aiming to maintain physical functioning. It includes treatments such as admission to hospital, intravenous fluids, and antibiotics but not attempted cardiopulmonary resuscitation and treatment in the intensive care unit. The third option, comfort care, was described as aiming to maximise comfort and to relieve pain. Only measures that provide comfort are performed. It is compatible with oxygen and analgesics but not with intravenous treatments and admission to hospital unless necessary to provide comfort. After these explanations, participants were asked about their preferences for care if they developed advanced dementia. Participants who were unable to select a level of care were considered "uncertain."

We assessed health literacy using the rapid estimate of adult literacy in medicine tool (REALM) ${ }^{30}$ This is a

Table 1|Characteristics of older people living in the community randomised to verbal description and video decision support groups. Figures are numbers (percentages) of participants unless stated otherwise

\begin{tabular}{|c|c|c|}
\hline Characteristics & Verbal $(n=106)$ & Video $(n=94)$ \\
\hline Mean (SD) age (years) & $75(8)$ & $75(8)$ \\
\hline Women & $59(56)$ & $57(61)$ \\
\hline \multicolumn{3}{|l|}{ Race: } \\
\hline Black/African-American & $35(33)$ & $24(26)$ \\
\hline White & $71(67)$ & $70(74)$ \\
\hline \multicolumn{3}{|l|}{ Health literacy*: } \\
\hline$\leq 6$ th grade ( $\leq 11$ years) & $19(18)$ & $16(17)$ \\
\hline 7-8th grades (12-14 years) & $15(14)$ & $9(10)$ \\
\hline$\geq 9$ th grade ( $\geq 14$ years) & $72(68)$ & $69(73)$ \\
\hline \multicolumn{3}{|l|}{ Education: } \\
\hline Elementary & $5(5)$ & $6(6)$ \\
\hline Some high school & $17(16)$ & $16(17)$ \\
\hline High school graduate & $19(18)$ & $17(18)$ \\
\hline Some college & $19(18)$ & $17(18)$ \\
\hline College graduate & $16(15)$ & $14(15)$ \\
\hline Postgraduate or professional & $29(27)$ & $24(26)$ \\
\hline Refused to say & $1(1)$ & 0 \\
\hline \multicolumn{3}{|l|}{ Marital status: } \\
\hline Married & $43(41)$ & $42(45)$ \\
\hline Widowed & $25(24)$ & $29(31)$ \\
\hline Divorced & $21(20)$ & $13(14)$ \\
\hline Never married & $17(15)$ & $10(10)$ \\
\hline \multicolumn{3}{|l|}{ Self reported health status: } \\
\hline Excellent & $15(14)$ & $9(10)$ \\
\hline Very good & $23(22)$ & $37(39)$ \\
\hline Good & $27(26)$ & $26(28)$ \\
\hline Fair & $30(28)$ & $19(20)$ \\
\hline Poor & $9(8)$ & $2(2)$ \\
\hline Refused to say & $2(2)$ & $1(1)$ \\
\hline Diagnosis of dementia†: & $12(11)$ & $6(6)$ \\
\hline $\begin{array}{l}\text { Previous relationship with } \\
\text { person with advanced dementia }\end{array}$ & $11(10)$ & $18(19)$ \\
\hline $\begin{array}{l}\text { Knowledge score before } \\
\text { randomisation } \neq\end{array}$ & 2.3 & 2.1 \\
\hline
\end{tabular}

*Assessed with rapid estimate of adult literacy in medicine (REALM). †Participants were asked if they had diagnosis of dementia.

łKnowledge score calculated by adding responses to five questions that test respondent's knowledge of advanced dementia. Each question has possible response of 1 (correct) or 0 (incorrect or unsure). Total knowledge score ranges from $0-5$, with higher scores indicating greater knowledge. 


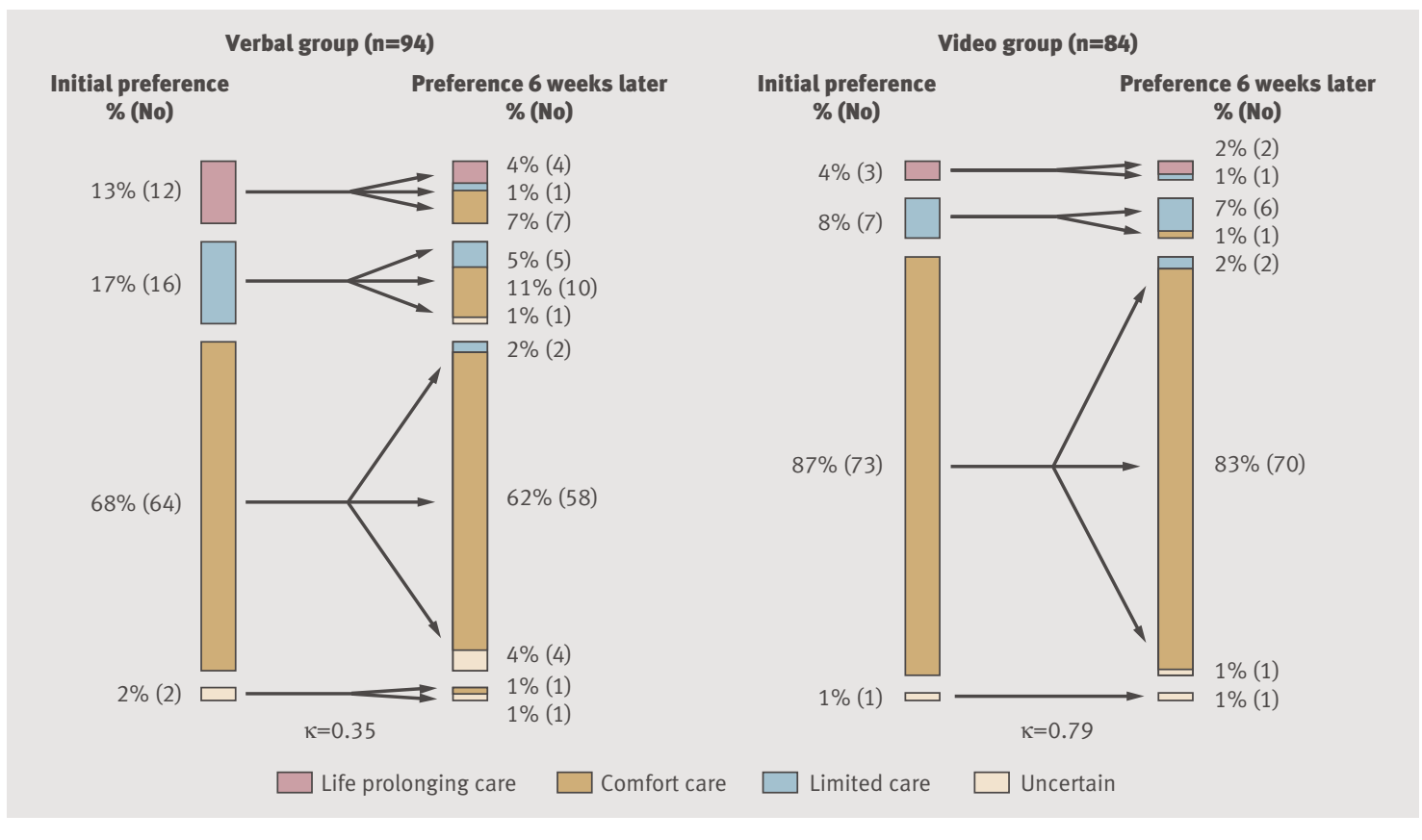

Fig 2 | Initial preferences and stability of preferences after six weeks

two to three minute English test of medically relevant vocabulary. It is a validated test of word pronunciation and has been shown to correlate well with tests that evaluate a range of literacy skills. ${ }^{30}$ As others have done, we defined three categories for health literacy based on the REALM scores: 6th grade and below (up to age 11; score 0-45); 7-8th grade (ages 12-13; 45-60); and 9th grade and above (age 14 and over; 61 $66) .^{3132}$

For those participants randomised to the video intervention group, we used a four point Likert scale to assess the perceived value of the video by asking participants whether they had a better understanding of the disease after viewing the video, if they were comfortable watching the video, if they would recommend the video to others, and whether they thought videos would be helpful for eliciting preferences for care in other diseases like cancer.

One interviewer (AEV) contacted participants by telephone six weeks after the initial interview to determine again what their preferences would be if they had advanced dementia in exactly the same manner as the initial interview. We chose a follow-up period of six weeks to ensure that an adequate amount of time elapsed from exposure to the intervention and to assess whether the video had an enduring effect.

\section{Statistical analysis}

Our analyses were based on the decision making group to which participants were randomised. The primary outcome measure was preferences for care if they developed advanced dementia categorised as four options (life prolonging, limited, comfort, or uncertain). Additional outcomes included change in knowledge scores before and after the intervention and the stability of preferences after six weeks.
All characteristics of participants and outcomes were described by using proportions for categorical variables and means (SD) for continuous variables. We used $\chi^{2}$ tests to compare preferences for care (life prolonging, limited, comfort, or uncertain) between the two groups.

Two sample $t$ tests compared change in knowledge scores before and after the intervention between the two groups. We used $\kappa$ statistics to summarise the stability of preferences six weeks after the clinic interview for each group and compared the proportions who changed preferences with Pearson $\chi^{2}$ exact test between the two groups.

The measure for the primary outcome analysis was the unadjusted difference in proportions of participants preferring comfort care between the two study groups. We conducted secondary analyses to identify factors associated with a preference for comfort care among all participants. Bivariate analyses determined the association between individual characteristics of participants (age, sex, race, education, marital status, health status, personal history of dementia, previous relationship with a person with advanced dementia, health literacy, and randomisation group) and a preference for comfort care with Fisher's exact test. Multivariable logistic regression analyses were used to identify factors independently associated with preferences for comfort care. Factors significant at 0.10 in the bivariate analyses were entered into a stepwise algorithm, retaining factors in the model that were significant at the 0.05 level. We used the variance inflation factor to diagnose colinearity among potential predictors.

All reported $\mathrm{P}$ values are two sided, with $\mathrm{P}<0.05$ considered as significant. The study was designed to detect a $25 \%$ difference in the proportion of participants 
choosing comfort care between the two groups, assuming the rate in the verbal group was $60 \%$. With a target of 100 patients in each group, the power of the study was estimated to be $>90 \%$. Data were analysed with SAS software, version 9.1 (SAS Institute, Cary, NC).

\section{RESULTS}

\section{Participant flow}

We approached 225 consecutive and potentially eligible patients, of whom 205 (92\%) agreed to be interviewed. Patients who declined did not differ significantly from the recruited participants in terms of age, sex, or race. The most common reason given for not participating was lack of time. Of the 205 recruited for the study, five were disqualified because their mental status questionnaire score was $<7$, resulting in a total of 200 study participants. Of these, 106 were randomised to the control group and 94 to the video intervention group (fig 1). Table 1 shows the baseline characteristics. Despite the randomisation process there were some baseline differences in the two groups, including diagnosis of dementia and previous relationship with someone with dementia,

\section{Outcomes}

Among the 106 participants receiving only the verbal narrative, $68(64 \%)$ chose comfort care, $20(19 \%)$ chose limited care, $15(14 \%)$ chose life prolonging care, and three $(3 \%)$ were uncertain of their preferences. Among the 94 who also saw the video, $81(86 \%)$ chose comfort care, eight $(9 \%)$ chose limited care, four $(4 \%)$ chose life prolonging care, and one $(1 \%)$ was uncertain of her preferences $\left(\chi^{2}=13.0, \mathrm{df}=3 ; \mathrm{P}=0.003\right)$. Thus a significantly greater proportion of participants in the video

\begin{tabular}{|c|c|c|c|c|c|}
\hline \multirow[b]{2}{*}{ Characteristics } & \multirow{2}{*}{$\begin{array}{l}\text { Frequency choosing } \\
\text { comfort care }\end{array}$} & \multirow{2}{*}{$\begin{array}{c}\text { Difference in \% } \\
\text { choosing comfort care } \\
(95 \% \mathrm{Cl})\end{array}$} & \multirow[b]{2}{*}{ Unadjusted $\mathrm{P}$ value } & \multicolumn{2}{|c|}{ Odds ratio $(95 \% \mathrm{Cl})$} \\
\hline & & & & Unadjusted & Adjusted \\
\hline \multicolumn{6}{|l|}{ Age (years): } \\
\hline$<80 \dagger$ & $104(71)$ & \multirow{2}{*}{$-12 \%(-0.3 \%$ to $25 \%)$} & \multirow{2}{*}{0.10} & \multirow{2}{*}{$2.0(0.9$ to 4.5$)$} & \multirow{2}{*}{-} \\
\hline$\geq 80$ & $45(83)$ & & & & \\
\hline \multicolumn{6}{|l|}{ Sex: } \\
\hline Female† & $88(76)$ & \multirow{2}{*}{$-3 \%$ (-16\% to $9 \%)$} & \multirow{2}{*}{0.62} & \multirow{2}{*}{0.8 (0.4 to 1.6$)$} & \multirow{2}{*}{-} \\
\hline Male & $61(73)$ & & & & \\
\hline \multicolumn{6}{|l|}{ Education: } \\
\hline «College graduate $\dagger$ & $79(68)$ & \multirow{2}{*}{$15 \%$ (3\% to $27 \%$ ) } & \multirow{2}{*}{0.021} & \multirow{2}{*}{$2.3(1.2$ to 4.6$)$} & \multirow{2}{*}{-} \\
\hline$\geq$ College graduate & $69(83)$ & & & & \\
\hline \multicolumn{6}{|l|}{ Marital status: } \\
\hline Not married $†$ & $82(71)$ & \multirow{2}{*}{$8 \%(-4 \%$ to $20 \%)$} & \multirow{2}{*}{0.25} & \multirow{2}{*}{$1.5(0.8$ to 2.9$)$} & \multirow{2}{*}{-} \\
\hline Married & $67(79)$ & & & & \\
\hline \multicolumn{6}{|l|}{ Health statusł: } \\
\hline Fair or poort & $35(58)$ & \multirow{2}{*}{$23 \%$ (9\% to $37 \%)$} & \multirow{2}{*}{0.001} & \multirow{2}{*}{$3.0(1.6$ to 6.0$)$} & \\
\hline Good or better & $111(81)$ & & & & - \\
\hline Diagnosis of dementia: & & & & & \\
\hline No† & $136(75)$ & $-30 /(-25 \%$ to $10 \%)$ & 10 & $00(02$ to 25$)$ & \\
\hline Yes & $13(72)$ & $-3 \%(-25 \%$ to $19 \%)$ & 1.0 & $0.9(0.3$ to 2.5$)$ & - \\
\hline Previous relationship with pe & anced dementia: & & & & \\
\hline No† & $125(73)$ & $100 /(-0)+250 /)$ & 0.6 & $10(0<$ to 10$)$ & \\
\hline Yes & $24(83)$ & $10 \%(-6 \%$ (0 $23 \%)$ & 0.30 & $1.0(0.0104 .9)$ & - \\
\hline Randomisation: & & & & & \\
\hline Verbalt & $68(64)$ & & & & \\
\hline Video & $81(86)$ & $22 \%(11 \%$ to $34 \%)$ & $<0.001$ & 3.5 (1.7 to 7.1$)$ & 3.9 (1.8 to 8.6$)$ \\
\hline Health literacy§: & & & & & \\
\hline$\leq 6$ th grade $\uparrow$ & $16(46)$ & & & & \\
\hline $7-8$ th grades & $14(58)$ & $13 \%(-13 \%$ to $38 \%)$ & & $1.7(0.6$ to 4.7$)$ & $\begin{array}{c}1.7(0.54 \text { to } \\
5.3)\end{array}$ \\
\hline$\geq 9$ th grade & $119(84)$ & $39 \%$ (21\% to $56 \%)$ & $<0.001$ & $\begin{array}{c}6.4(2.9 \text { to } \\
14.4)\end{array}$ & $\begin{array}{l}4.1 \text { (1.6 to } \\
10.8)\end{array}$ \\
\hline Race: & & & & & \\
\hline Black/ African-American† & $30(51)$ & & & 5.2 (2.6 to & \\
\hline White & $119(84)$ & $34 \%$ (19\% to 48\%) & $<0.001$ & 10.4) & 2.9 (1.3 to 6.6$)$ \\
\hline $\begin{array}{l}\text { *For multivariable analysis, } \\
\text { †Reference category. } \\
\text { †Health status was one of ex } \\
\text { §Assessed with rapid estimat }\end{array}$ & $\begin{array}{l}\text { excluded from model if } \\
\text { ood, good, fair, or poor } \\
\text { acy in medicine (REALI }\end{array}$ & hey were not related to ou & tcome-that is, choosir & g comfort care- & -at $P<0.05$. \\
\hline
\end{tabular}




\section{WHAT IS ALREADY KNOWN ON THIS TOPIC}

Advance care planning is a complex process involving communication of future health states such as advanced dementia

Visual images might be helpful to improve decision making and communication of complex information regarding what type of medical care patients would want at the end of life

\section{WHAT THIS STUDY ADDS}

Video images of advanced dementia improved knowledge for patients choosing the type of medical care they would like if they developed advanced dementia

Patients who viewed a video decision support tool of advanced dementia after hearing a verbal description were more likely to choose a comfort oriented approach compared with patients solely listening to a verbal narrative of the disease

Patients using the video decision support tool had more stable preferences for end of life care over time

Video decision support tools might be most useful for patients with low health literacy

group opted for comfort care (difference 22\%, 95\% confidence interval $11 \%$ to $34 \%$ ).

Mean knowledge scores (range 0-5) were significantly higher in the video group than in the control group (4.5 (SD 1.0) v 3.8 (SD 1.3), respectively; $\mathrm{P}<0.001)$. The mean increase in knowledge scores for the video group was 2.4 (2.1 to 2.7 ) and 1.5 (1.2 to 1.9$)$ for the control group, which was significant $(\mathrm{P}<0.001)$.

Table 2 shows the unadjusted differences in proportions of participants and odds ratios preferring comfort care for each of the characteristics. The factors associated with a greater likelihood of preferring comfort care among all participants were being a college graduate or higher, good or better health status, greater health literacy, white race, and randomisation to the video group. The first four factors were highly correlated: those with higher degree of education were more likely to have better health status, greater health literacy, and more likely to be white; those with better health status were more likely to have greater health literacy and were more likely to be white; and those with greater health literacy were more likely to be white (all with $\mathrm{P}<0.05$ ). The variance inflation factors, however, were all less than 2.5 when we tested these four factors in the regression model, which indicated weak evidence of multicollinearity. After inclusion of these variables in a multivariable logistic regression model, participants randomised to the intervention group had a greater likelihood of opting for comfort care (adjusted odds ratio 3.9, 1.8 to 8.6). Other factors independently associated with opting for comfort care included a health literacy level of greater than 9th grade $(4.1,1.6$ to 10.8$)$ and white race $(2.9,1.3$ to 6.6$)$ (table 2).

Six weeks after the initial clinic visit, we attempted to contact each participant by telephone. Among the 94 $(89 \%)$ in the control group who could be contacted, 27 $(29 \%)$ changed their preferences; the $\kappa$ statistic for preference stability was 0.35 (0.15 to 0.54 ) (fig 2 ). Among the $84(89 \%)$ participants contacted in the video group, five $(6 \%)$ changed their preferences; the $\kappa$ statistic for preference stability was 0.79 (0.62 to 0.98$)$. After six weeks, the proportion of participants changing preferences was lower in the video group $(\mathrm{P}<0.001)$.

The video decision support tool was highly acceptable to participants: 83 of $94(88 \%)$ found the video "very helpful" or "somewhat helpful"; 80 (85\%) said they were "very comfortable" or "somewhat comfortable" viewing the video; 89 (95\%) said they would "definitely" or "probably" recommend the video to others; and $78(83 \%)$ thought that using videos for other diseases (such as cancer) would be "very helpful" or "somewhat helpful." There were no adverse events in either group.

\section{DISCUSSION}

\section{Principal findings}

When presented with the possibility of developing advanced dementia, older patients living in the community are more likely to choose comfort as the primary goal of care after viewing a video of a patient with the disease and listening to a verbal description rather than just hearing a verbal description of advanced dementia. Moreover, viewing the video improved knowledge of advanced dementia and enhanced stability of preferences for treatment over time compared with hearing only the verbal narrative. Finally, health literacy seems to be associated with end of life preferences among older patients.

\section{Comparison with other studies}

To the best of our knowledge, this study represents the first randomised controlled trial in a group of older patients of a video decision support tool for decision making at the end of life. In our previous before and after investigation of the advanced dementia video conducted in healthy middle aged participants, the video promoted preferences for comfort care, but it was not a randomised trial, was conducted with a younger healthy cohort, and did not follow the stability of preferences over time..$^{20}$ Our current study extends this earlier work by showing the efficacy of the video in a randomised controlled trial among older patients. Moreover, the participants in the video group were more likely to have improved knowledge after the video and stable preferences over time. The stability of preferences is a critical consideration in evaluating preferences at the end of life ${ }^{33-40}$ and suggests a more accurate reflection of patients' values and wishes.

\section{Strengths and limitations}

Our study has several important limitations and numerous strengths. Firstly, the research staff collecting data at baseline and at the immediate and six week follow-up interviews were not blinded to randomisation, which could have introduced bias into our findings. Previous randomised studies of interventions aimed at improving end of life decision making, however, have seldom been blinded because limiting the number of interviewers eases the burden on participants of addressing difficult and often painful subject matter. ${ }^{8-10}$ Furthermore, participants might disclose whether they viewed the video or not. We attempted 
to reduce the influence of this potential bias by using structured interviews and outcome measures. Secondly, despite randomisation there were some baseline differences between the two groups. This can be expected in a relatively small sample. Thirdly, videos can be manipulated to favour a particular perspective. Our study used one video of a white woman with dementia. We did not assess responses of participants to videos of people of different sex and race. Fourthly, we asked participants for their preferences in the context of a research study. The next step would be to investigate whether patients and physicians would document their preferences in the medical record or complete an advance directive ${ }^{41}$ Finally, our sample was primarily white and African-American and drawn from primary care clinics in teaching hospitals in metropolitan Boston. Thus, our findings might not be generalisable to other minority groups (such as Latinos and Asian-Americans).

\section{Policy implications and future research}

Previous uses of video decision support tools have primarily focused on helping patients to make treatment or screening decisions. ${ }^{42}$ Our use of video redirects attention to the underlying health state by clarifying the nature of the condition about which patients are expected to make decisions. Our use of video portrays the illness to add a sense of verisimilitude that might be lacking in verbal descriptions. Moreover, these images might offer a more objective and straightforward approach to describe complex medical conditions, which is particularly pertinent to patients with low health literacy. In the US such patients are more likely to be elderly and African-American ${ }^{31}$ and are among the most vulnerable populations in our healthcare system. As the video led to better knowledge of advanced dementia, our study supports the claim made by others that pictorial or visual methods improve decision making processes. ${ }^{16-22}$

Previous studies have suggested that non-white people receive and opt for more aggressive end of life care. ${ }^{43-49}$ The reason for this observation is not well elucidated but might be, in part, because of variation in the quality of counselling they receive and their understanding of that counselling. As we have shown elsewhere, ${ }^{22}$ our study lends additional support to the notion that health literacy potentially mediates the role of race in end of life decision making, and video decision support tools offer an approach to circumvent this disparity. Future work is needed to explore this finding as health literacy was highly correlated with other variables and our study lacked adequate power to conduct detailed analyses of mediation.

The next step in using videos is to explore other diseases and the goals of care with video portrayals. We suspect that numerous other diseases and interventions, such as advanced cancer and cardiopulmonary resuscitation, would also be more accurately conveyed to patients through a visual medium than solely by verbal descriptions. As we have shown here and elsewhere, ${ }^{29}$ criteria regarding the necessary content and editing of each video portrayal must be carefully considered before clinical application of these videos.

Active debate exists surrounding the development of decision support technologies, especially when highly subjective content (patients' narratives and testimonials) and non-traditional media (video) are used. ${ }^{5051}$ While important steps have been taken to develop objective criteria for the development and field testing of decision support tools, ${ }^{5253}$ more research is needed particularly as they apply to the use of video.

Including patients in the decision making process has been an important yet complex advance in modern medical care. To secure the delivery of high quality end of life care, patients must be informed regarding their decision making. Education of patients using video decision support tools can improve their comprehension of disease states such as advanced dementia that are difficult to envision solely with words. Future work could extend the use of video decision support tools to other disease states such as advanced cancer and the goals of care. We have shown that video decision support tools enhance elderly patients' decision making by ensuring that it is both more informed and consistent over time.

We thank the patient and her family, who agreed to be filmed for the purposes of educating and improving decision making at the end of life for all patients. We also thank Claus Hamann, Katherine Hesse, Juergen Bludau, Laurel Yates, Peggy Edson, Ruth Kandel, and Aretha Delight Davis for their contribution to the project.

Contributors: AEV, MKP-O, MJB, MRG, EFC, EDA, and SLM were responsible for study concept and design. $A E V$ and $A E-J$ acquired the data, which was analysed and interpreted by AEV, MKP-O, YC, and SLM. AEV, MKP-O, MJB, MRG, EDA, and SLM drafted the manuscript. AEV, MKPO, MJB, MRG, KLM, EFC, EDA, AE-J, and SLM supervised the study and critically revised the manuscript for important intellectual content. YC did the statistical analysis. AEV, MJB, MRG, and SLM obtained funding. AEV, MKP-O, MJB, KLM, EFC, EDA, AE-J, and SLM were responsible for administrative, technical, and material support. AEV is guarantor. Funding: AEV was supported by a George Bennett Fellowship from the Foundation for Informed Medical Decision Making, a New Investigator Research Grant from the Alzheimer's Association, and a Center for Excellence Career Development Award from the Hartford Foundation. Role of the sponsor: None of the foundations participated in the collection, analysis, or interpretation of the data or in preparation, review or approval of the manuscript.

Competing interests: None declared.

Ethical approval: The protocol was approved by the institutional review board of each participating institution and all participants provided informed consent

1 Lo B, Snyder L. Care at the end of life: guiding practice where there are no easy answers. Ann Intern Med 1999;130:772-4.

2 Council on Scientific Affairs. Good care of the dying patient. American Medical Association. JAMA 1996;275:474-8.

3 Lynn J. Measuring quality of care at the end of life: a statement of principles. J Am Geriatr Soc 1997;45:526-7.

4 Sachs GA, Ahronheim JC, Rhymes JA, Volicer L, Lynn J. Good care of dying patients: the alternative to physician-assisted suicide and euthanasia. J Am Geriatr Soc 1995;43:553-62.

5 Emanuel LL, Danis M, Pearlman RA, Singer PA. Advance care planning as a process: structuring the discussions in practice. J Am Geriatr Soc 1995;43:440-6.

6 Gillick MR. A broader role for advance medical planning. Ann Intern Med 1995;123:621-4.

7 Finucane TE, Shumway JM, Powers RL, D’Alessandri RM. Planning with elderly outpatients for contingencies of severe illness: a survey and clinical trial. J Gen Intern Med 1988;3:322-5. 
8 SUPPORT. A controlled trial to improve care for seriously ill hospitalized patients. The study to understand prognoses and preferences for outcomes and risks of treatments (SUPPORT). The SUPPORT Principal Investigators. JAMA 1995;274:1591-8.

9 Hofmann JC, Wenger NS, Davis RB, Teno J, Connors AF Jr, Desbiens N, et al. Patient preferences for communication with physicians about end-of-life decisions. SUPPORT Investigators. Study to Understand Prognoses and Preference for Outcomes and Risks of Treatment. Ann Intern Med 1997;127:1-12.

10 Covinsky KE, Fuller JD, Yaffe K, Johnston CB, Hamel MB, Lynn J, et al. Communication and decision-making in seriously ill patients: findings of the SUPPORT project. The Study to Understand Prognoses and Preferences for Outcomes and Risks of Treatments. J Am Geriatr Soc 2000;48(5 suppl):S187-93.

11 Tulsky JA, Fischer GS, Rose MR, Arnold RM. Opening the black box: how do physicians communicate about advance directives? Ann Intern Med 1998;129:441-9.

12 Roter DL, Larson S, Fischer GS, Arnold RM, Tulsky JA. Experts practice what they preach: a descriptive study of best and normative practices in end-of-life discussions. Arch Intern Med 2000;160:3477-85.

13 Smith AK, Ries AP, Zhang B, Tulsky JA, Prigerson HG, Block SD. Resident approaches to advance care planning on the day of hospital admission. Arch Intern Med 2006;166:1597-602.

14 Tulsky JA, Chesney MA, Lo B. See one, do one, teach one? House staff experience discussing do-not-resuscitate orders. Arch Intern Med 1996;156:1285-9.

15 Tulsky JA, Chesney MA, Lo B. How do medical residents discuss resuscitation with patients? J Gen Intern Med 1995;10:436-42.

16 Frosch DL, Kaplan RM, Felitti VJ. A randomized controlled trial comparing internet and video to facilitate patient education for men considering the prostate specific antigen test. J Gen Intern Med 2003;18:781-7.

17 Morgan MW, Deber RB, Llewellyn-Thomas HA, Gladstone P, Cusimano RJ, O'Rourke K, et al. Randomized, controlled trial of an interactive videodisc decision aid for patients with ischemic heart disease. J Gen Intern Med 2000;15:685-93.

18 Edwards A, Elwyn G, Mulley A. Explaining risks: turning numerica data into meaningful pictures. $B M J$ 2002;324:827-30.

19 Houts PS, Doak CC, Doak LG, Loscalzo MJ. The role of pictures in improving health communication: a review of research on attention, comprehension, recall, and adherence. Patient Educ Couns 2006;61:173-90.

20 Volandes AE, Lehmann LS, Cook EF, Shaykevich S, Abbo ED, Gillick MR. Using video images of dementia in advance care planning. Arch Intern Med 2007;167:828-33.

21 Volandes AE, Ariza M, Abbo ED, Paasche-Orlow M. Overcoming educational barriers for advance care planning in latinos with video images. I Palliat Med 2008:11:700-6.

22 Volandes AE, Paasche-Orlow M, Gillick MR, Cook EF, Shaykevich S, Abbo ED, et al. Health literacy not race predicts end-of-life care preferences. J Palliat Med 2008;11:754-62.

23 Wolfson C, Wolfson DB, Asgharian M, M'Lan CE, Ostbye T, Rockwood K, et al. A reevaluation of the duration of survival after the onset of dementia. N Engl J Med 2001;344:1111-6.

24 Larson EB, Shadlen MF, Wang L, McCormick WC, Bowen JD, Teri L, et al. Survival after initial diagnosis of Alzheimer disease. Ann Intern Med 2004:140:501-9.

25 Pfeiffer E. A short portable mental status questionnaire for the assessment of organic brain deficit in elderly patients. J Am Geriatr Soc 1975;23:433-41.

26 Sclan SG, Reisberg B. Functional assessment staging (FAST) in Alzheimer's disease: reliability, validity, and ordinality. Int Psychogeriatr 1992;4(suppl 1):55-69.

27 National Cancer Institute. Making health communication programs work: a planner's guide. Bethesda, MD: US National Institutes of Health, 1997. www.cancer.gov/pinkbook.

28 Grant BK, Sloniowski J. Documenting the documentary: close readings of documentary film and video. Detroit: Wayne State University Press, 1998

29 Gillick MR, Volandes AE. The psychology of using and creating video decision aids for advance care planning. In: Lynch TE, ed. Psychology of decision making in medicine and health care. New York, NY: Nova Science Publishers, 2007:193-206.
30 Davis TC, Long SW, Jackson RH, Mayeaux EJ, George RB, Murphy PW, et al. Rapid estimate of adult literacy in medicine: a shortened screening instrument. Fam Med 1993;25:391-5.

31 Paasche-Orlow MK, Parker RM, Gazmararian JA, Nielsen-Bohlman LT, Rudd RR. The prevalence of limited health literacy. J Gen Intern Med 2005;20:175-84.

32 Davis TC, Wolf MS, Bass PF 3rd, Thompson JA, Tilson HH, Neuberger $\mathrm{M}$, et al. Literacy and misunderstanding prescription drug labels. Ann Intern Med 2006;145:887-94.

33 Everhart MA, Pearlman RA. Stability of patient preferences regarding life-sustaining treatments. Chest 1990;97:159-64.

34 Danis M, Garrett J, Harris R, Patrick DL. Stability of choices about lifesustaining treatments. Ann Intern Med 1994;120:567-73.

35 Emanuel LL, Emanuel EJ, Stoeckle JD, Hummel LR, Barry MJ. Advance directives. Stability of patients' treatment choices. Arch Intern Med 1994;154:209-17.

36 Carmel S, Mutran EJ. Stability of elderly persons' expressed preferences regarding the use of life-sustaining treatments. Soc Sci Med 1999;49:303-11.

37 Rosenfeld KE, Wenger NS, Phillips RS, Connors AF, Dawson NV, Layde P, et al. Factors associated with change in resuscitation preference of seriously ill patients. The SUPPORT Investigators. Study to Understand Prognoses and Preferences for Outcomes and Risks of Treatments. Arch Intern Med 1996;156:1558-64.

38 Ditto PH, Smucker WD, Danks JH, Jacobson JA, Houts RM, Fagerlin A et al. Stability of older adults' preferences for life-sustaining medical treatment. Health Psychol 2003;22:605-15.

39 Straton JB, Wang NY, Meoni LA, Ford DE, Klag MJ, Casarett D, et al. Physical functioning, depression, and preferences for treatment at the end of life: the Johns Hopkins Precursors Study. J Am Geriatr Soc 2004;52:577-82.

40 Lockhart LK, Ditto PH, Danks JH, Coppola KM, Smucker WD. The stability of older adults' judgments of fates better and worse than death. Death Stud 2001;25:299-317.

41 Abbo ED, Sobotka S, Meltzer DO. Patient preferences in instructional advance directives. I Palliat Med 2008;11:555-62.

42 O'Connor AM, Stacey D, Rovner D, Holmes-Rovner M, Tetroe J, Llewellyn-Thomas $\mathrm{H}$, et al. Decision aids for people facing health treatment or screening decisions. Cochrane Database Syst Rev 2001;(3):CD001431.

43 Garrett JM, Harris RP, Norburn JK, Patrick DL, Danis M. Life-sustaining treatments during terminal illness: who wants what? J Gen Intern Med 1993;8:361-8.

44 Caralis PV, Davis B, Wright K, Marcial E. The influence of ethnicity and race on attitudes toward advance directives, life-prolonging treatments, and euthanasia. J Clin Ethics 1993;4:155-65.

45 O’Brien LA, Grisso JA, Maislin G, LaPann K, Krotki KP, Greco PJ, et al. Nursing home residents' preferences for life-sustaining treatments. IAMA 1995;274:1775-9.

46 Blackhall LJ, Frank G, Murphy ST, Michel V, Palmer JM, Azen SP. Ethnicity and attitudes towards life sustaining technology. Soc Sci Med 1999;48:1779-89.

47 Crawley L, Payne R, Bolden J, Payne T, Washington P, Williams S. Palliative and end-of-life care in the African American community. JAMA 2000;284:2518-21.

48 Hopp FP, Duffy SA. Racial variations in end-of-life care. J Am Geriatr Soc 2000;48:658-63.

49 Klessig J. The effect of values and culture on life-support decisions. West J Med 1992;157:316-22.

50 Khangura S, Bennett C, Stacey D, O'Connor AM. Personal stories in publicly available patient decision aids. Patient Educ Couns 2008;73:456-64.

51 Winterbottom A, Bekker HL, Conner M, Mooney A. Does narrative information bias individual's decision making? A systematic review. Soc Sci Med 2008;67:2079-88.

52 Elwyn G, O’Connor A, Stacey D, Volk R, Edwards A, Coulter A, et al. Developing a quality criteria framework for patient decision aids: online international Delphi consensus process. BMJ 2006;333:417.

53 Evans R, Elwyn G, Edwards A, Watson E, Austoker J, Grol R. Toward a model for field-testing patient decision-support technologies: qualitative field-testing study. J Med Internet Res 2007;9:e21.

Accepted: 3 February 2009 